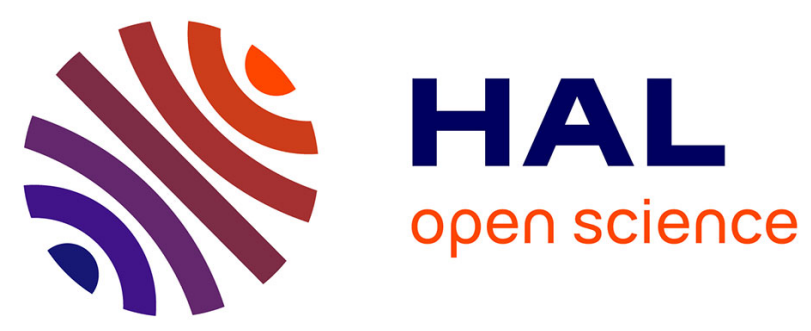

\title{
Multi-scales modelling for the behaviour of damaged concrete
}

Frédéric Grondin, H. Dumontet, A. Ben Hamida, G. Mounajed, H. Boussa

\section{To cite this version:}

Frédéric Grondin, H. Dumontet, A. Ben Hamida, G. Mounajed, H. Boussa. Multi-scales modelling for the behaviour of damaged concrete. Cement and Concrete Research, 2007, 37 (10), pp.1453-1462. 10.1016/j.cemconres.2007.05.012 . hal-01007093

\section{HAL Id: hal-01007093 https://hal.science/hal-01007093}

Submitted on 13 Dec 2017

HAL is a multi-disciplinary open access archive for the deposit and dissemination of scientific research documents, whether they are published or not. The documents may come from teaching and research institutions in France or abroad, or from public or private research centers.
L'archive ouverte pluridisciplinaire $\mathbf{H A L}$, est destinée au dépôt et à la diffusion de documents scientifiques de niveau recherche, publiés ou non, émanant des établissements d'enseignement et de recherche français ou étrangers, des laboratoires publics ou privés. 


\title{
Multi-scales modelling for the behaviour of damaged concrete
}

\author{
F. Grondin ${ }^{\mathrm{a}, *}$, H. Dumontet ${ }^{\mathrm{b}}$, A. Ben Hamida ${ }^{\mathrm{b}}$, G. Mounajed $^{\mathrm{c}}$, H. Boussa $^{\mathrm{c}}$ \\ ${ }^{a}$ Institut de Recherche en Génie Civil et Mécanique, UMR-CNRS 6183, Ecole Centrale de Nantes, 1 rue de la Noë BP 9210144321 Nantes Cedex 3, France \\ ${ }^{\mathrm{b}}$ Université Pierre et Marie Curie-Paris 6, UMR-CNRS 7190, Institut Jean le Rond d'Alembert, 4 place Jussieu,75252 Paris Cedex 5, France \\ ${ }^{\mathrm{c}}$ Centre Scientifique et Technique du Bâtiment, MOCAD, 84 Avenue Jean Jaurès Champs-sur-Marne 77447 Marne-la-Vallée Cedex 2, France
}

\begin{abstract}
The aim of this study is to investigate and to simulate damage mechanisms of concrete under fire conditions. A micro-mechanical model has been developed by coupling the effective moduli approach with a finite element model based on the representation of the heterogeneous materials random microstructure. Numerical simulations have been carried out in order to analyze the effective behaviour of confined concrete samples subjected to high temperatures coupled to compressive loads and to localize damage on the microstructure scale. These simulations show that the 'transient thermal strain', noticed during experimental tests, is due to the thermal damage of concrete.
\end{abstract}

Keywords: Modeling (E); Micromechanics (C); Microstructure (B); High-Performance Concrete (E); High temperature

\section{Introduction}

Materials used in civil engineering are often under coupled loads according to their exploitation or to the environment. For example, in nuclear building, these materials are loaded at high temperatures. These heterogeneous and porous materials have a complex behaviour, which is quasi-brittle under mechanical, thermal and hydraulic loads which are often coupled. Experimental tests are made to observe micro-cracks and to define their evolution and their influence on the durability of cement-based materials. The development of numerical tools to model the thermo-hydro-mechanical behaviour of damaged cement-based materials appears important in complement to experimental approach to give a predictive analysis of degradations of structures. Some damage models for cement-based materials suggested in the literature review are based on various theoretical tools of the damage mechanism. Often, they are according to a macroscopic approach for the behaviour of materials. Damage of concrete has been specifically studied with isotropic models [1], with anisotropic models [2], with the microplane model [3,4], or recently with the macroscopic model developed by Ung and Mounajed [5,6].

\footnotetext{
* Corresponding author. Tel.: +332 403716 68; fax: +332 40372535 . E-mail address: frederic.grondin@univ-nantes.fr (F. Grondin).
}

In this paper, we have chosen a micro-mechanical approach to model the coupled thermo-mechanical behaviour of heterogeneous media. The multi-scales approach appears interesting by its possibility to take into account microstructure data like the size distribution or the specific behaviour of each constituent. The homogenization process allows to characterize the equivalent homogeneous behaviour of the material on the macroscopic scale. But, the interest of the multi-scales approach is also the possibility to localize fields on the microscopic scale, as local stresses or strains. So, the local damage of the concrete microstructure can be studied from these local fields and the crack mechanism can be then followed. Multi-scales approaches are generally based on the choice of a Representative Elementary Volume (REV) of the heterogeneous material microstructure. A uniform strain is applied and local stresses are obtained by solving a cellular problem on the REV. Then, the homogenized behaviour law is defined by relying the average of local stresses and the uniform strain applied. A lot of homogenization methods have been suggested in the literature review. They are distinguished by the choice of the REV and the method used to apply the macroscopic load [7]. Also, it can be distinguished by homogenization of explicit methods and numerical methods. Explicit methods are based on idealized representations of the microstructure and analytical resolutions of cellular problems. Even if they are simple and for some of them are sufficient to predict the behaviour of heterogeneous materials, they 
do not allow to accurately localize micro-mechanical fields. Numerical methods allow to consider a more realistic microstructure but need a numerical resolution of cellular problems. Also, numerical methods allow to localize micro-mechanical fields. Some numerical methods have been recently proposed to study the behaviour of cement-based materials. We can cite the numerical model developed in the National Institute of Standard Technology (NIST) [8], the finite element model developed at the University of Technology of Delft (TUDelft) [9] and the finite element model developed in the Ecole Polytechnique Fédérale de Lausanne (EPFL) [10,11].

In the objective to model a realistic microstructure of cementbased materials, we have used a micro-mechanical numerical approach. The proposed micro-mechanical approach is based on a REV of the material within all heterogeneities, aggregates and pores, that are distributed by a random process in this volume, according to the real aggregate size distribution. This tool $[12,13]$ is implemented in the finite element code Symphonie [14]. Cellular problems of the homogenization approach are solved by a finite element method with non-linear behaviour laws for constituents. The interest of this development, thus the important difference with classical homogenization methods, is the possibility to localize mechanical and thermal fields on the constituents scale. The macroscopic damage model MODEV [5,6] is introduced in this work on the constituents scale of the REV. Two mechanical damage modes have been considered: one damage according to a volumetric strain, and one damage according to a deviatoric strain. A coupling between the model Digital Concrete, the damage model and homogenization methods has been made to calculate the nonlinear macroscopic behaviour of damaged cement-based materials.
This approach has been applied to study the thermo-mechanical behaviour of High-Performance Concrete (HPC) under coupled loads without and with damage.

In the first part of this paper, we introduce the numerical model Digital Concrete and the associated algorithm. In the second part, we describe the macroscopic damage model and its thermodynamical formulation. Then, we present the formulation of the non-linear cellular problem. In the last part, applications are presented on the behaviour of concrete at high temperatures under a compressive load. The macroscopic strain behaviour and the homogenized rigidity of concrete are calculated. Results obtained have been compared to experimental measurements. Finally, the localization of damage on the constituents scale is analyzed at different temperatures levels.

\section{The Digital Concrete model}

The numerical model, Digital Concrete [12,13], allows to built a realistic Representative Elementary Volume of multiphases materials. A specific algorithm has been developed to introduce a random phases distribution with different properties in an unspecified grid. This grid could represent all sorts of heterogeneous geomaterials. Here the random characteristic of this model is used to describe the microstructure of cementbased materials in taking into account the constituents volume fraction used in concrete. In this application, all grid elements have cement paste properties in first. Then, the aggregate size distribution is introduced in the REV following experimental microstructural observations (Fig. 1). The properties of the grid elements located in an aggregate area are those of this

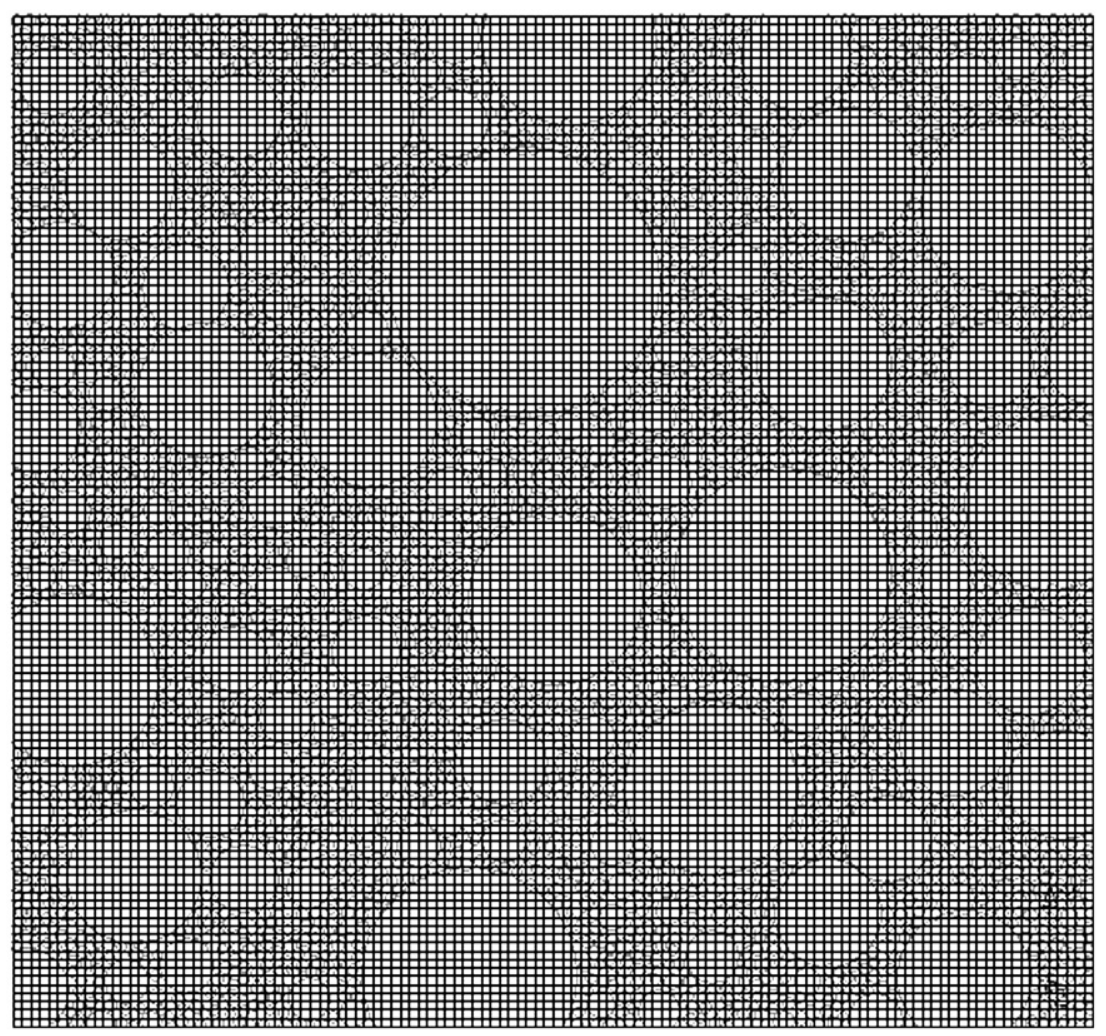

Fig. 1. A Representative Elementary Volume of the Digital Concrete model. 
aggregate. The grid is used as a finite element mesh of the REV for the multi-scales approach. The cellular problem can be then solved with a finite element code and gives access by average to the equivalent thermo-mechanical behaviour of cement-based materials. In the following applications, the finite element code used is Symphonie developed by the MOCAD division of the Scientific and Technical Center for Building (CSTB) [14]. On the REV scale, the components can be considered homogeneous. The size of the REV is chosen to take into account significative heterogeneities. The ratio of sizes between the REV and the heterogeneities has been particularly studied. The stability of the results has been tested according to the random distribution of heterogeneities in the volume. Small variations have been noticed of the homogenized behaviour when the random distribution changes. Similar variations are noticed on experimental measurements for different samples of a mixed concrete. Numerical tests were performed to analyze the stability of results depending of the REV size $L$ and the maximal diameter of inclusion $D_{\max }$. It was noted that for a ratio of $L / D_{\max }>4$, the effective Young modulus does not significantly change even with different distribution of the heterogeneities (Fig. 2). In the same way, stability tests have been performed to define the ratio $L / D_{\max }$ for hydraulic conductivity problems. The same ratio $\left(L / D_{\max }>4\right)$ has been retained [15].

\section{The damage model MODEV}

Because the presence of aggregate, cement paste, microcavities and micro-cracks in the material, the mechanical behaviour of concrete cannot be modeled by only one strain mechanism. According to experimental observations, Ung and Mounajed [5,6] have suggested a macroscopic damage model, MODEV, with two mechanical damage mechanisms, a damage associated to the deviatoric strain and a damage associated to the volumetric strain. In order to model the unilateral behaviour of concrete, only the deviatoric damage is taken into account for the compressive behaviour and both deviatoric and volumetric damages are introduced for the tensile behaviour. The damage mechanism depends on three strain energies, the total elastic strain energy, the distorsion energy to take into account the slip mechanism between the cracks lips, and the volumetric strain energy to take into account the influence of the cracks growth according to the hydrostatical stress. So the elastic thermodynamical potential $\psi$ is written as follows $[5,6]$ :

$$
\begin{aligned}
& \rho \psi\left(\varepsilon, d^{\mathrm{s}}, d^{\mathrm{d}}, \beta^{\mathrm{s}}, \beta^{\mathrm{d}}\right)=\frac{1}{2}\left(1-\eta d^{\mathrm{s}}-(1-\eta) d^{\mathrm{d}}\right) \boldsymbol{C}: \varepsilon: \varepsilon \\
& \quad+\varphi^{\mathrm{s}}\left(\beta^{\mathrm{s}}\right)+\varphi^{\mathrm{d}}\left(\beta^{\mathrm{d}}\right)
\end{aligned}
$$

where $\rho$ is the mass density, $\varepsilon$ the strain tensor, $\boldsymbol{C}$ the stiffness tensor, $d^{\mathrm{s}}$ and $d^{\mathrm{d}}$ are respectively the volumetric and the deviatoric damage variables and the total damage variable is defined by $1-d=1-\eta d^{\mathrm{s}}-(1-\eta) d^{\mathrm{d}}$,where $\eta$ is a parameter which is adapted according to the problem type following the work of Mazars [1]. $\varphi^{\mathrm{s}}\left(\beta^{\mathrm{s}}\right)$ and $\varphi^{\mathrm{d}}\left(\beta^{\mathrm{d}}\right)$ are strain energies respectively according to hardening variables of the volumetric damage and the deviatoric damage. So, state laws associated to this potential are given by:

$$
\begin{aligned}
\boldsymbol{\sigma} & =\rho \frac{\partial \psi}{\partial \varepsilon} \\
Y & =\rho \frac{\partial \psi}{\partial d}=-\frac{1}{2} \boldsymbol{C}: \varepsilon: \varepsilon \\
B^{\mathrm{s}} & =\rho \frac{\partial \psi}{\partial \beta^{\mathrm{s}}}=\rho \frac{\partial \varphi^{\mathrm{s}}}{\partial \beta^{\mathrm{s}}} \\
B^{d} & =\rho \frac{\partial \psi}{\partial \beta^{d}}=\rho \frac{\partial \varphi^{d}}{\partial \beta^{d}}
\end{aligned}
$$

where $\boldsymbol{\sigma}$ is the stress tensor, $B^{\mathrm{s}}$ and $B^{\mathrm{d}}$ the damage evolution variables according to the volumetric and the deviatoric mechanism. According to the equivalent strain introduced by Mazars [1], two equivalent strains are retained in this model, $\tilde{\varepsilon}^{\mathrm{s}}$ for the volumetric mechanism and $\tilde{\varepsilon}^{\mathrm{d}}$ for the deviatoric mechanism. These equivalent strains correspond to the local slip in micro-cracks and the hydrostatic state. They are obtained from the deviatoric strain part $\varepsilon^{\mathrm{d}}$ and the volumetric strain part $\varepsilon^{\mathrm{s}}$ of the strain tensor by:

$\tilde{\varepsilon}^{\mathrm{s}}=\varepsilon^{\mathrm{H}}=\frac{1}{3} \operatorname{tr} \varepsilon$

$\tilde{\varepsilon}^{\mathrm{d}}=\sqrt{\left(\varepsilon_{1}^{\mathrm{d}}\right)^{2}+\left(\varepsilon_{2}^{\mathrm{d}}\right)^{2}+\left(\varepsilon_{3}^{\mathrm{d}}\right)^{2}}+\alpha_{\mathrm{c}} \varepsilon^{\mathrm{H}}$

where $\varepsilon_{i}^{d}$ are main strains of the deviatoric strain tensor and $\alpha_{c}$ a coupling coefficient reflecting the material consolidation under a

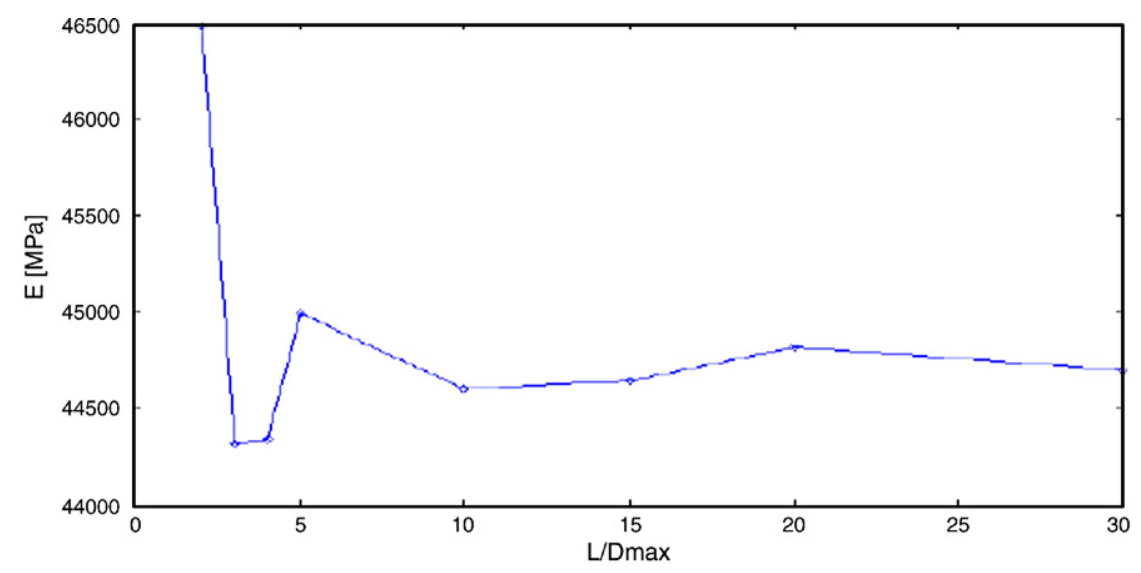

Fig. 2. Variation of homogenized Young modulus versus ratio $L / D_{\max }$ (REV size/inclusion diameter). 


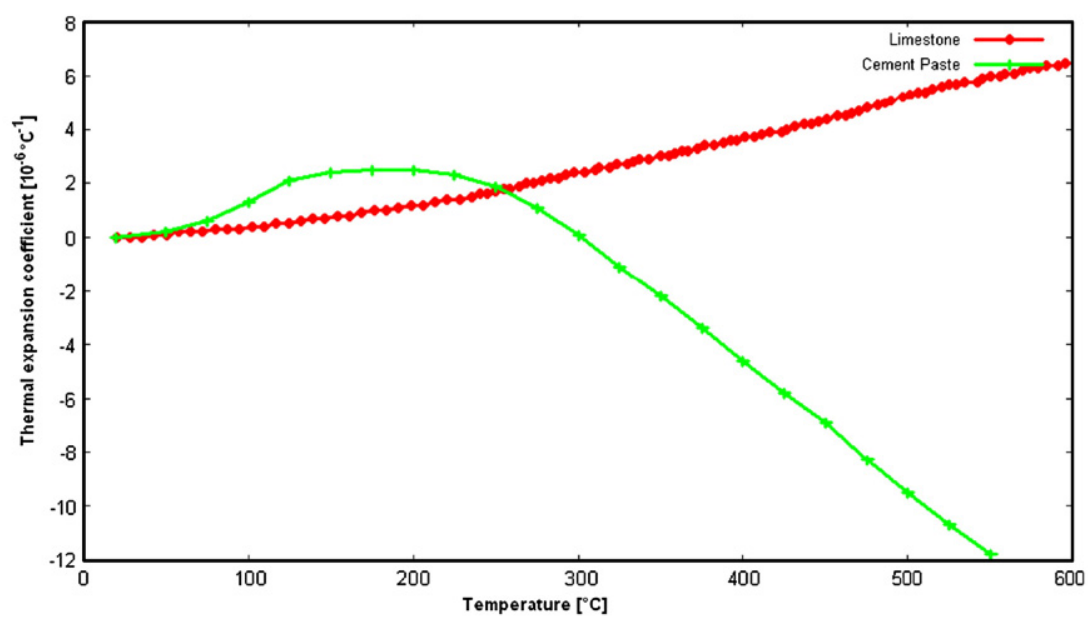

Fig. 3. Evolution of thermal expansion of the cement paste and calcareous aggregate versus temperature. Experimental results [16].

compressive load. If $\tilde{\varepsilon}^{\mathrm{s}}$ and $\tilde{\varepsilon}^{\mathrm{d}}$ reach a threshold, the associated damage variables $d^{\mathrm{s}}$ and $d^{\mathrm{d}}$ evolve. The initial damage threshold is defined by experimental tests, uniaxial tensile tests and shear tests, with:

$\tilde{\varepsilon}_{0}^{\mathrm{s}}=\frac{f_{\mathrm{t}}}{3 E}(1-2 v)$

$\tilde{\varepsilon}_{0}^{\mathrm{d}}=\frac{\sqrt{2} f_{\text {cis }}}{2 G}=\frac{\sqrt{2} f_{\text {cis }}}{E}(1+v)$

where $E$ is the Young modulus, $G$ the shear modulus, $v$ the Poisson's ratio of the material, $f_{\mathrm{t}}$ its tensile strength and $f_{\text {cis }}$ its shear strength.

Ung [5] has suggested these following evolutions of the volumetric damage and the deviatoric damage, according to the Mazars's model [1]:

$d^{\mathrm{s}}=1-\frac{\tilde{\varepsilon}_{0}^{\mathrm{s}}}{\tilde{\varepsilon}^{\mathrm{s}}} \exp \left[-B_{\mathrm{t}}\left(\tilde{\varepsilon}^{\mathrm{s}}-\tilde{\varepsilon}_{0}^{\mathrm{s}}\right)\right]$

$d^{\mathrm{d}}=1-\exp \left[-B_{\mathrm{c}}\left(\tilde{\varepsilon}^{\mathrm{d}}-\tilde{\varepsilon}_{0}^{\mathrm{d}}\right)\right]$

where $B_{\mathrm{t}}$ is a damage parameter related to the fracture energy to limit the mesh sensitivity and $B_{\mathrm{c}}$ a material parameter associated to its compressive strength.

This macroscopic damage model has been implemented in the finite element code Symphonie. We have adapted it on the scale of the REV for simulations of the behaviour of concrete at high temperatures.

\section{The homogenized non-linear thermo-mechanical behaviour}

The REV of a heterogeneous material, is formed by two solid phases, a matrix defined by the volume $V_{\mathrm{m}}$, and inclusions, aggregate in concrete for example, defined by the volume $V_{\mathrm{r}}$. We write $V$ the volume of the REV, $\Gamma_{m r}$ interfaces between the matrix and aggregate and $\partial V$ the exterior boundary of the volume $V$. In the objective to model the behaviour of damaged cementbased materials, non-linear thermo-mechanical behaviour laws have been suggested for the phases. A uniform temperature $\Delta T$ and a uniform strain field tensor $\boldsymbol{E}$ are applied to the REV. These loads imply local displacements fields $\boldsymbol{u}(y)$, local strain fields $\varepsilon(y)$ and local stress fields $\boldsymbol{\sigma}(y)$ in each point $y$ of $V$ which are solutions of the following cellular problem:

$\nabla . \boldsymbol{\sigma}(y)=0$

$\sigma(y)=\boldsymbol{C}(y, \varepsilon(y)):(\varepsilon(y)-\alpha(y, T) \Delta T)$

$\varepsilon(y)=\frac{1}{2}\left(\nabla(\boldsymbol{u})+\nabla(\boldsymbol{u})^{t}\right)$

$\|\sigma . \boldsymbol{n}\|=0\|\boldsymbol{u}(y)\|=0$ on $\Gamma_{\mathrm{mr}}$

$\boldsymbol{u}=\boldsymbol{E} . y \quad$ on $\partial V$

where $C(y, \varepsilon(y))$ is the stiffness tensor of the material phases depending on the strain of phases and $\boldsymbol{\alpha}(y, T)$ is the thermal expansive tensor of the material phases depending on the temperature. The notation symbol \|. || describes the "jump" of a field on an interface and $\boldsymbol{n}$ is the exterior unit normal of the surface. The stiffness tensor is depending on the strain state according to the damage model as follows:

$\boldsymbol{C}(y, \boldsymbol{\varepsilon}(y))=\left[1-\eta d^{\mathrm{s}}(\varepsilon(y))-(1-\eta) d^{\mathrm{d}}(\varepsilon(y))\right] \boldsymbol{C}(y)$

where $\boldsymbol{C}(y)$ is the stiffness tensor of the phases at the initial state and $\eta$ a parameter which is adapted according to the problem type following the work of Mazars [1]. In the following

Table 1

Mechanical parameters of the HPC M100C phases at $20^{\circ} \mathrm{C}$

\begin{tabular}{lll}
\hline & Cement paste & Aggregate \\
\hline$E[\mathrm{MPa}]$ & 15000 & 75000 \\
$v$ & 0.2 & 0.28 \\
$\alpha\left[{ }^{\circ} \mathrm{C}^{-1}\right]$ & $5.7910^{-6}$ & $4.1615110^{-6}$ \\
$f_{\mathrm{c}}[\mathrm{MPa}]$ & 80 & 180 \\
$f_{\mathrm{t}}[\mathrm{MPa}]$ & 3 & 10 \\
$f_{\text {cis }}[\mathrm{MPa}]$ & 6 & 20 \\
$G_{\mathrm{f}}[\mathrm{N} / \mathrm{mm}]$ & 0.1 & 0.15 \\
\hline
\end{tabular}


Table 2

Aggregate size distribution of the HPC M100C [16]

\begin{tabular}{lclc}
\hline$D(\mathrm{~mm})$ & $\mathrm{Vf}(\%)$ & $D(\mathrm{~mm})$ & $\mathrm{Vf}(\%)$ \\
\hline 25 & 2 & 4 & 3 \\
20 & 8 & 3.15 & 1 \\
16 & 10 & 2.5 & 3 \\
12.5 & 8 & 2 & 1 \\
10 & 6 & 1.6 & 1 \\
8 & 4 & 1.25 & 4 \\
6.3 & 2 & 1 & 18 \\
5 & 2 & & \\
\hline
\end{tabular}

applications, we have chosen the value $\eta=1 / 3$ in considering that the damage is distributed according to $1 / 3$ of a volumetric damage and $2 / 3$ of a deviatoric damage.

The non-linear homogenized behaviour is defined by the average relation between the average stresses $\langle\boldsymbol{\sigma}\rangle_{V}$ and the average strains $\langle\boldsymbol{\varepsilon}\rangle_{V}$ where $\boldsymbol{\sigma}$ is the stress tensor solution of the cellular problem (12-17). The secant formulation of this behaviour law can be written as follows:

$$
\begin{aligned}
\Sigma & =\langle\boldsymbol{\sigma}\rangle_{V}=\frac{1}{|V|} \int_{V} \boldsymbol{\sigma}(y) d y \\
& =\boldsymbol{C}^{\mathrm{hom}}\left(\langle\varepsilon\rangle_{V}\right):\left(\langle\varepsilon\rangle_{V}-\alpha^{\mathrm{hom}}(T) \Delta T\right) \\
& =\boldsymbol{C}^{\text {hom }}(\boldsymbol{E}):\left(\boldsymbol{E}-\alpha^{\mathrm{hom}}(T) \Delta T\right)
\end{aligned}
$$

where $\boldsymbol{C}^{\text {hom }}(\boldsymbol{E})$ is the homogenized stiffness tensor and $\boldsymbol{\alpha}^{\text {hom }}(T)$ the homogenized thermal expansion tensor.

\section{Behaviour of High-Performance Concrete at high temperature under a compressive load}

This study is in the framework of the durability of civil engineering building in fire conditions. The objective is to understand and to model damage and strain mechanisms of concrete at high temperature up to $600{ }^{\circ} \mathrm{C}$.

In experimental tests performed on cement samples, a purely thermal damage without strains has been identified. It occurs mainly in cement paste with dehydration and important mass loss beyond $120^{\circ} \mathrm{C}$ and can be explained by different chemical transformations. Various models have been proposed in order to take into account this thermal damage [17-19]. Due to the restrained thermal strains on a macroscopic and mesoscopic scale, mechanical damage of thermal origin accompanied with strains also occurs [20].

It can be also observed in experimental tests a decrease of strains of concrete when it is submitted to high temperature coupled to a compressive load. This phenomenon is called by some researchers as 'transient thermal creep' or 'transient thermal strain'. These observations have been interpreted by a lot of theories [21,22] and some models have been suggested to calculate this behaviour $[21,23,24]$. We propose here another explanation of this phenomenon from results of simulations. For the simulations, the multi-scales approach is coupled to the model Digital Concrete and to the damage model in order to analyze local damage mechanisms.

\subsection{Concrete phases properties and experimental results}

The application presented in this paper concerns the behaviour of concrete which has been studied in experimental fire tests $[25,16]$. Its composition, also its mixture process, is presented in detail in the work of Gaweska Hager [16]. It is a High-Performance Concrete (HPC M100C) which contains a cement paste with a water cement ratio of $E / C=0.3$. The cement used is of type CPA CEM I 52.5 PM ES CP2 (Le Havre). The HPC M100C contains calcareous aggregates (Boulonnais) and limestone (La Seine). The cylindrical coupon samples tested have the following dimensions: $160 \times 320 \mathrm{~mm}$.

Mechanical properties of the Young modulus $(E)$ of the cement paste and the compressive strength $\left(f_{\mathrm{c}}\right)$ of calcareous aggregates are given by experimental tests [16]. The evolutions of thermal expansive coefficient $(\alpha)$ of the cement paste and of aggregate versus temperature are given by experimental tests $[22,16]$ and presented in Fig. 3. The Young moduli of aggregate and Poisson's ratio of the cement paste and aggregate are taken in the literature review [26,27]. All phases properties are presented in Table 1 at

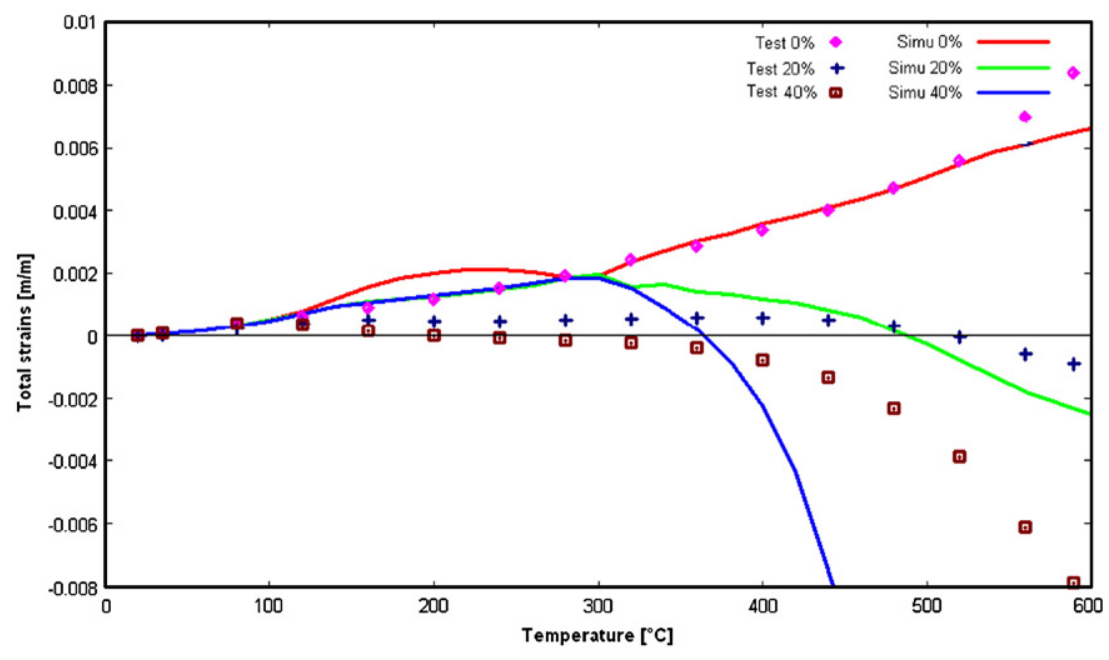

Fig. 4. Comparisons between calculated strains (Simu) for an axisymmetric problem and measured strains (test) [16]. 


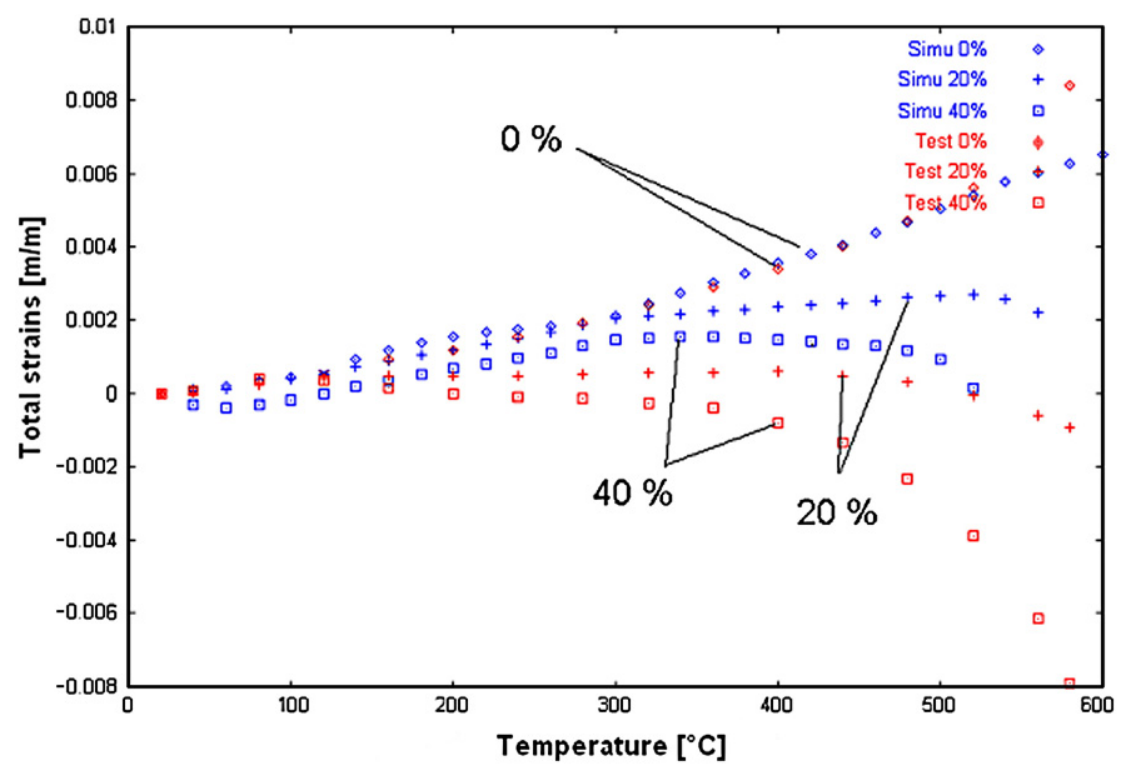

Fig. 5. Comparisons between macroscopic calculated strains (Simu) and measured strains (Test) of the HPC M100C at high temperature under a compressive load.

$20{ }^{\circ} \mathrm{C}$ and the aggregate size distribution retained is presented in Table 2 for each volume fraction (Vf) according to aggregates diameter $(D)$ from experimental data [16].

The compressive load is taken equal to $0 \%, 20 \%$ or $40 \%$ of the compressive strength of the HPC M100C which is equal to $120 \mathrm{MPa}$. The temperature rate is equal to $10^{\circ} \mathrm{C} / \mathrm{min}$ and the test starts at $20{ }^{\circ} \mathrm{C}$ up to $600{ }^{\circ} \mathrm{C}$. Experimental results are presented in Fig. 4.

First of all we give some comments on these experimental results. The cement paste expands up to $250^{\circ} \mathrm{C}$. That is due to the expansion of the water in pores. At $100^{\circ} \mathrm{C}$ the liquid water begins to change to water vapor until $250^{\circ} \mathrm{C}$. Then, this water vapor goes out of the cement paste across the porous network. So, a shrinkage of the cement paste can be observed. The phase change of water is taken into account in the thermal expansion coefficient of the cement paste (Fig. 3). We can note that until $250{ }^{\circ} \mathrm{C}$ and without a compressive load the volumetric damage according to the hydrostatic state is high.
If the concrete sample is under a compressive load, the expansion of each phase is hindered until $250^{\circ} \mathrm{C}$. According to a weakness of the microstructure, that is could be interpreted by a microstructural effect on the behaviour of concrete, the damage increases at temperature higher than $250^{\circ} \mathrm{C}$. Differential dilations in the microstructure between the cement paste and aggregate seem to be responsible of the concrete degradation. At high temperature, the cement paste begins to shrink and aggregates continue to expand. So, aggregates apply a compressive load on the cement paste. This phenomenon underlines a Poisson's effect and a tensile effect along the perpendicular axis $O x$ to the compressive axis.

\subsection{Comparison with simulations}

The REV used for the following simulations contains a homogeneous cement paste and heterogeneous aggregates. A uniform applied pressure load and a temperature rate $\Delta T$ are applied. The geometrical and mechanical properties of the

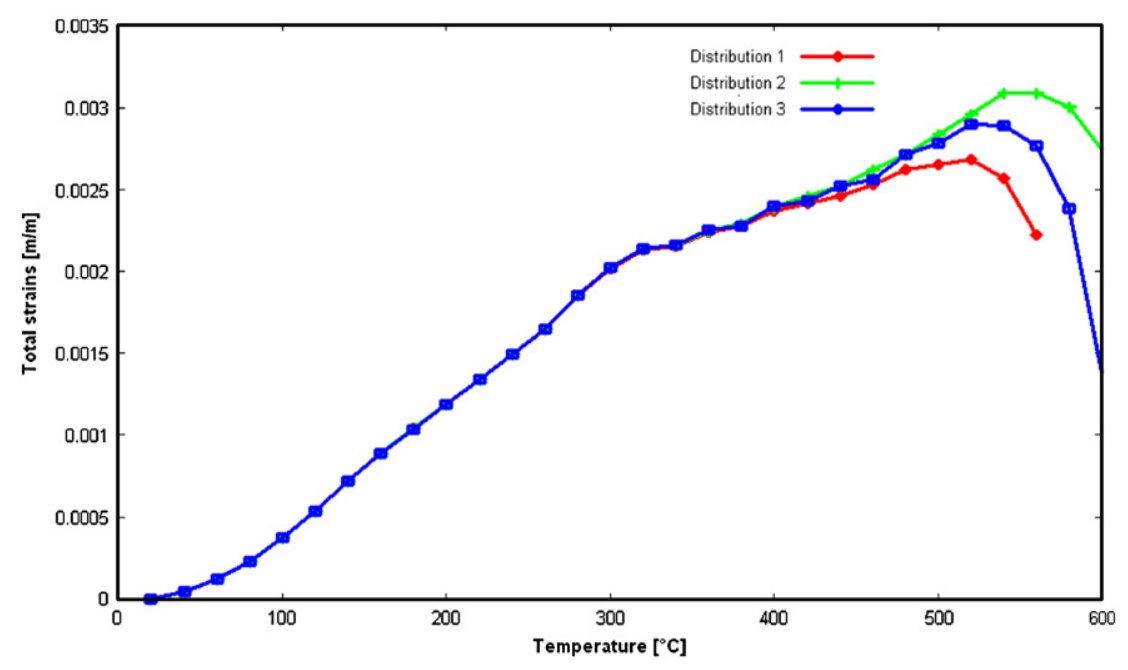

Fig. 6. Evolution of the strain for three different positioning of aggregates in the REV. 
Table 3

Young modulus of the HPC M100C

\begin{tabular}{|c|c|c|c|c|}
\hline & Simulati & & & \\
\hline & Simu 1 & Simu 2 & Simu 3 & Average \\
\hline$E$ [GPa] & 50.88 & 50.85 & 50.86 & 50.86 \\
\hline & Tests $[2$ & & & \\
\hline & Test 1 & Test 2 & Test 3 & Average \\
\hline$E$ [GPa] & 52.2 & 50.5 & 49.8 & 50.8 \\
\hline
\end{tabular}

Comparison between calculated (Simu) and experimental results (Test), [25].

constituents are taken following Tables 1 and 2 . The tensile strength $f_{\mathrm{t}}$ and the shear strength $f_{\text {cis }}$ of the two concrete phases are identified by an inverse homogenization method. The coefficient $G_{\mathrm{f}}$ which is a parameter of the crack energy is defined by empirical criterions [19].

Various REV further described have been generated from these data. The cellular problem (Eqs. (12)-(17)) is solved in taking into account local damage variables $d^{\mathrm{s}}$ and $d^{\mathrm{d}}$ of each phase. And the homogenized thermo-mechanical secant behaviour law of concrete is characterized from Eq. (18). Calculated macroscopic strains (Simu0\%, Simu20\%, Simu40\%) have been compared to experimental measurements (Test $0 \%$, Test $20 \%$, Test $40 \%$ ) in Figs. 4 and 5 following the REV.

In a first study, we have adopted a REV with a ratio of $L /$ $D_{\max } \geq 4$, dimensions of $100 \times 100 \mathrm{~mm}$ and plane strains conditions. The results are presented in Fig. 5. If no compressive load is applied (case 0\%), numerical results are in good agreement with experimental tests. If a compressive load is coupled to the imposed temperature, calculated strains are higher than experimental values. The difference between calculated strains values and measured strains values are of about $10^{-3}$ in the test with the coupled mechanical and thermal load.

In a second study, axisymmetric simulations have been performed by exploiting symmetric conditions to model a quarter of a concrete sample with dimensions of $80 \times 160 \mathrm{~mm}$. The results are presented in Fig. 4. In this case the curves' shapes are in better agreement with experimental measurements. The differences between simulations and measurements are of the same order of magnitude as the experimental dispersion measured on other concrete samples [28]. One can thus conclude that the degradation of concrete observed at high

Table 4

Results on elastic and thermo-elastic values of the HPC M100C

\begin{tabular}{|c|c|c|c|c|}
\hline \multirow[t]{2}{*}{ Models } & $E$ & $K$ & $G$ & $a$ \\
\hline & [GPa] & {$[\mathrm{GPa}]$} & [GPa] & {$\left[10^{-6}{ }^{\circ} \mathrm{C}^{-1}\right]$} \\
\hline Simu & 50.9 & 41.9 & 20.2 & 4.17 \\
\hline Test [16] & 51.9 & - & - & 4.23 \\
\hline $\mathrm{SC}$ & 49.9 & 39.5 & 20 & 4.47 \\
\hline HS & 51.9 & 41.8 & 20.7 & 4.47 \\
\hline
\end{tabular}

Comparisons between calculated results (Simu) and experimental results [16] and classical homogenization methods results: self-constituent scheme (SC), Hashin-Shtrikman bounds (HS). temperatures can be modeled by the differential dilations between the cement paste and aggregates which are explicitly taken into account in the REV.

To study the influence of the random generation of aggregates on the macroscopic behaviour, calculations have been performed with three random generations of aggregates in the REV. Results can been compared in Fig. 6 and show that only the crack state at high temperatures changes. It can be explained by different distribution of the damage in the various generated REV.

\subsection{Calculation of the equivalent thermo-elastic behaviour law}

The effective thermo-elastic behaviour has been compared to experimental values obtained by Pimienta [25] and Gaweska Hager [16] for the HPC M100C. First of all, with three REV with different positioning of aggregate are considered. The equivalent Young modulus $(E)$ is compared to experimental measurements [25] at ambient temperature and without a compressive load in Table 3.

Also, the bulk modulus $(K)$, the shear modulus $(G)$ and the thermal expansive coefficient $(\alpha)$ are in good agreement with results obtained with experimental values [16] and with classical homogenization methods such as Hashin-Shtrikman bounds (HS) and the self-consistent scheme (SC). Results are presented in Table 4. In comparison to classical homogenization methods, the model presented in this paper is not limited to linear problem and allows to localize the calculated fields in each point of the REV.

Under a compressive load and high temperature, the effective rigidity decreases and the behaviour of the damaged concrete becomes anisotropic. Results have been compared to experimental values [16] in Table 5. In fact, Young modulus calculated along the compressive axis $(O y)\left(E_{y}\right)$ are higher than obtained along the perpendicular axis $(O x)\left(E_{x}\right)$. The compressive load in coupling with the temperature applied increases the local damage in the volume. Anyway, the thermal dilation is obstructed by the compressive load until $250^{\circ} \mathrm{C}$. Then, tensile effects appear along the $O x$ axis. So, the damage increases highly along this axis while the compressive load obstructs the aggregate dilation.

\subsection{Analysis of local fields}

The numerical modeling allows also to visualize local damage in each point of the material microstructure and at each

Table 5

Homogenized Young modulus of the HPC M100C at high temperatures

\begin{tabular}{lllll}
\hline$T\left[{ }^{\circ} \mathrm{C}\right]$ & 20 & 120 & 250 & 400 \\
\hline$E_{y}(0 \%)[\mathrm{GPa}]$ & 51 & 36.5 & 35.2 & 18.9 \\
Tests $(0 \%)[\mathrm{GPa}]$ & 51.9 & 39.4 & 28.8 & 22 \\
$E_{x}(20 \%)[\mathrm{GPa}]$ & 51 & 44.9 & 43.6 & 25.4 \\
$E_{y}(20 \%)[\mathrm{GPa}]$ & 51 & 45.9 & 45 & 30.6 \\
$E_{x}(40 \%)[\mathrm{GPa}]$ & 51 & 39.2 & 38.9 & 24.1 \\
$E_{y}(40 \%)[\mathrm{GPa}]$ & 51 & 38.3 & 38 & 29.1 \\
\hline
\end{tabular}


load step. By this way, we can follow the evolutions of the volumetric and deviatoric damages. Isovalues of the volumetric damage at $240{ }^{\circ} \mathrm{C}$ and $260{ }^{\circ} \mathrm{C}$ for the HPC M100C under a compressive load equal to $20 \%$ of the compressive strength are presented in Fig. 7. It can be observed in these figures, the directions of the evolution of the damage. Without a compressive load, the damage evolves along all directions and if a compressive load is applied the damage evolves along the
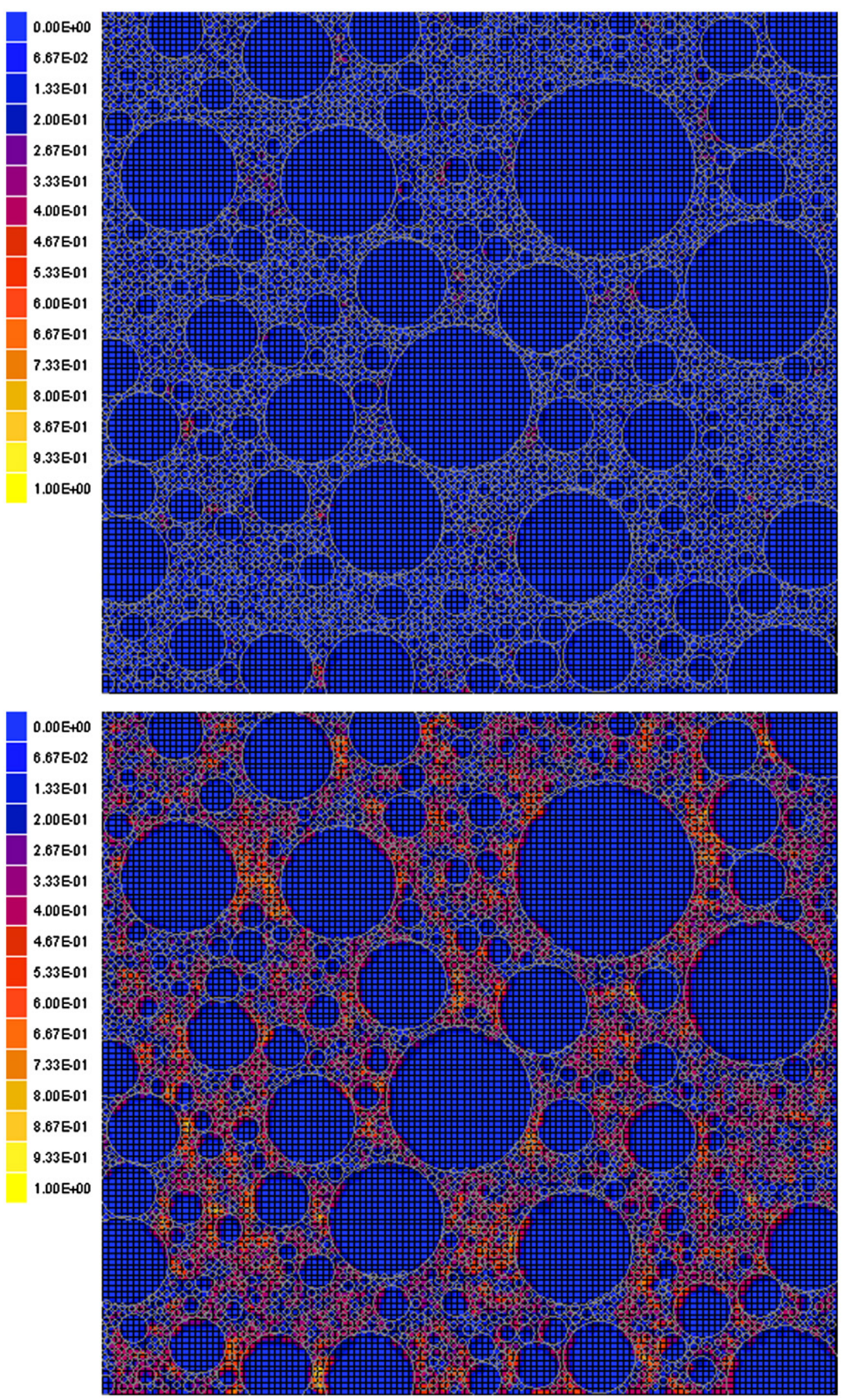

Fig. 7. Volumetric damage localized in the $\mathrm{HPC} \mathrm{M} 100 \mathrm{C}$ at $240{ }^{\circ} \mathrm{C}$ and $260^{\circ} \mathrm{C}$ under a compressive load equal to $20 \%$ of the compressive strength. 
compressive axis. This phenomenon has been also observed in experimental tests [16].

\section{Conclusion}

In this paper, we have presented a numerical multi-scales approach to model the non-linear thermo-mechanical behaviour of heterogeneous materials. A coupling of both the effective homogenization method, the microscopic damage model [5] and the numerical model Digital Concrete $[12,13]$ has been performed. This numerical model allows to implement, in a random process, all heterogeneities (aggregate, pores, ...) in a Representative Elementary Volume in order to approach the realistic concrete microstructure. Non-linear homogenization thermo-mechanical cellular problems have been solved by the finite elements method. Homogenized behaviour laws of the equivalent material are obtained as the relation of average values. Applications to the behaviour of concrete under coupled mechanical and thermal loading have been performed. At the ambient temperature the effective behaviour has been compared in good agreement with experimental measurements [25,16], and with classical homogenization results. At high temperature the damage behaviour is also in good agreement with experimental measurements $[25,16]$. The localization of damage values has allowed to follow the concrete degradation versus temperature and to investigate the influence of the compressive load.

Numerical classical models are often macroscopic models and add a new parameter in the thermo-mechanical behaviour law to take into account the 'transient thermal creep' [18,29,30]. In this study, no terms are added in the thermo-mechanical behaviour law. The model presented in this paper takes into account interactions of the behaviour of phases in the concrete microstructure. The micro-mechanical approach allows to show the structural effect of the damage in concrete at high temperatures under a mechanical load.

The numerical tools presented in this paper could be adapted to different materials and coupled to different damage models. These tools are currently completed by a model which takes into account chemical effects due to the cement paste hydration in order to model the behaviour of young cement-based materials. Also, we expect to take into account the interfacial transition zone in concrete between the cement paste and aggregate. This interfacial transition zone has mechanical properties which are different of that of the cement paste and aggregate, and is of influence on the behaviour of concrete.

\section{References}

[1] J. Mazars, Application de la mécanique de l'endommagement au comportement non linéaire et à la rupture du béton de structure, Thèse de doctorat, Université Pierre et Marie Curie (1984).

[2] J. Simo, J. Ju, Strain and stress based continuum formulation, International Journal of Solids and Structures 23 (7) (1987) 821-840.

[3] Z. Bazant, Microplane model for strain controlled inelastic behaviour, Mechanics of Engineering Materials (1984) 45-59.

[4] J. Ozbolt, Microplane Model for Quasibrittle Materials, Part I, Theory, Bericht 96-1a, Institut fr Werkstoffe im Bauwesen, Universität Stuttgart, aF, 1996.
[5] H. Ung Quoc, Théories de dégradation du béton et développement d'un nouveau modèle d'endommagement en formulation incrémentale et tangente, Thèse de doctorat, Ecole Nationale des Ponts et Chausées (2003).

[6] H. Ung Quoc, G. Mounajed, A new F.E. tangent damage model MODEV for concrete structures, 11th International Conference on Fracture ICFXI, 2005.

[7] M. Bornert, T. Bretheau, P. Gilormini, Homogénéisation en mécanique des matériaux, vol. 1, Hermès Sciences Publications, Paris, 2001, Tome.

[8] D. Bentz, E. Garboczi, N. Martys, Application of digital-image-based models to microstructure, transport properties, and degradation of cementbased materials, in: H. Jennings (Ed.), Modelling of Microstructure and Its Potential for Studying Transport Properties and Durability, Kluwer Academic publisher, 1996, pp. 167-185.

[9] P. Stroeven, M. Stroeven, Assessment of packing characteristics by computer simulation, Cement and Concrete Research 29 (1999) 1201-1206.

[10] A. Guidoum, P. Navi, C. Huet, 3d numerical analysis of long term behaviour on concrete-like composite material, Proceedings of Research and Development in the Field of Dams, CIGB-ICOLD, Crans-Montana, 1995, pp. 289-298.

[11] C. Huet, Coupled size and boundary-condition effects in viscoelastic heterogeneous and composite bodies, Mechanics of Materials 31 (12) (1999) 787-829.

[12] G. Mounajed, Conception et développement du modèle aléatoire béton numérique dans le code de calcul aux éléments finis symphonie, Research report cstb, CSTB, 2001. http://mocad.cstb.fr.

[13] G. Mounajed, Exploitation du nouveau modèle béton numérique dans symphonie: Concept, homogénéisation du comportement thermomécanique des BHP et simulation de l'endommagement thermique, Cahiers du CSTB 3421, CSTB, 2002.

[14] G. Mounajed, SYMPHONIE, general multi-physics and multi-scales F.E. code, CSTB, http://mocad.cstb.fr. 1991.

[15] F. Grondin, Modélisation multi-échelles du comportement thermo-hydromécanique matériaux hétérogènes-applications aux matériaux cimentaires sous sollicitations sévères, These de doctorat, Université Pierre et Marie Curie (2005).

[16] I. Gaweska Hager, Comportement à haute température des bétons à haute performance-évolution des principales propriétés mécaniques, Thèse de doctorat, Ecole Nationale des Ponts et Chaussées (2004).

[17] F.-J. Ulm, O. Coussy, Z. Bazant, The Chunnel fire: 1. Chemoplastic softening in rapidly heated concrete, Journal of Engineering Mechanics 125 (3) (1999) 272-282.

[18] D. Gawin, F. Pesavento, B. Schrefler, Modelling of deformations of high strength concrete at elevated temperatures, Materials and Structures 37 (268) (2004) 218-236.

[19] A. Menou, Etude du comportement thermomécanique des bétons à haute temperature: Approche multi-échelles de l'endommagement thermique, Thèse de doctorat, Université de Pau et des Pays de l'Adour (2004).

[20] C. Nielsen, C. Pearce, N. Bicanic, Theoretical model of high temperature effects on uniaxial concrete member under elastic restraint, Magazine of Concrete Research 54 (4) (2002) 239-249.

[21] G. Khoury, B. Grainger, G. Sulivan, Transient thermal strain of concrete: literature review, conditions with specimen and behaviour of individual constituents, Magazine of Concrete Research 132 (1985) 131-144.

[22] Z. Bazant, M. Kaplan, Concrete at high temperatures: material properties and mathematical models, Concrete Design and Construction Series, Longman Group Limited, 1996.

[23] J. Stabler, G. Baker, On the form of free energy and specific heat in coupled thermo-elasticity with isotropic damage, International Journal of Solids and Structures 37 (2000) 4691-4713.

[24] K. Willam, I. Rheee, B. Shing, Interface damage model for thermomechanical degradation of heterogeneous materials, Computer Methods in Applied Mechanics and Engineering 193 (2004) 3327-3350.

[25] P. Pimienta, Evolution des caractéristiques des bhp soumis à des températures élevées, résistances en compression et modules d'élasticité, Final report bhp 2000, CSTB, 1999.

[26] G. Dreux, J. Festa, Nouveau guide du béton, Eyrolles, 1995. 
[27] C. Tourenq, J.-L. Durville, E. Massieu, Les propriétés des roches: guide pratique, Mémento, Mines et Carrières, vol. 3, LCPC, 1997.

[28] F. Holst, Mechanical properties of high strength concrete at high temperatures, Interim Report M7:2, HPC Structures, Lund Institute of Technology, 1994.
[29] G. Khoury, Strain components of nuclear-reactor-type concretes during first heat cycle, Nuclear Engineering and Design 156 (1995) 313-321.

[30] W. Nechnech, F. Meftah, J. Reynouard, An elasto-plastic damage model for plain concrete subjected to high temperatures, Engineering Structures 24 (2002) 597-611. 